\title{
The Impact of Shopbots on Electronic Markets
}

\author{
Michael D. Smith \\ mds@cmu.edu \\ H. John Heinz III School of Public Policy and Management \\ Carnegie Mellon University \\ 4800 Forbes Avenue \\ Pittsburgh, PA 15217
}

Available at http://www.heinz.cmu.edu/ mds/isem.pdf

Forthcoming, Journal of the Academy of Marketing Science, Fall 2002, Volume 30, Number 4, pp. 442-450.

Acknowledgements: I thank Erik Brynjolfsson, Kirthi Kalyanam, three anonymous referees and participants at the Marketing Sciences Institute's "Marketing to and Serving Customers Through the Internet" Conference (December 2001) for valuable comments on this paper. Christopher Muenchhoff generously provided data regarding customer behavior at Dealtime.com and providing invaluable insight into the shopbot market. The Carnegie Bosch Institute and the Berkman Foundation provided generous financial support. 


\title{
The Impact of Shopbots on Electronic Markets
}

\begin{abstract}
$\underline{\text { ABSTRACT }}$
Internet shopbots are automated tools that allow customers to easily search for prices and product characteristics from online retailers. Some market observers have predicted that shopbots will benefit consumers at the expense of retailers. In this view, shopbots will radically reduce consumer search costs, reduce retailer opportunities to differentiate their products, and as a result will drive retailer margins toward zero.

However, a review of the literature suggests that, while shopbots may place pressure on retailer margins in some circumstances, retailers retain numerous opportunities to differentiate their products, leverage brand names, set strategic prices, and reduce the effectiveness of consumer search at shopbots. The paper closes by identifying significant questions for future research.
\end{abstract}




\section{Introduction}

'It sounds like a consumer's dream — and a merchant's nightmare... Shopping robots are capable of searching for goods on hundreds of Web sites in seconds, putting unprecedented pressure on Web retailers to beat their competitors' prices."

“Attack of the Robots,” Wall Street Journal, December 1998

"[Internet technologies are] like an arms race in which both sides develop increasingly powerful weapons."

Yannis Bakos (1998)

According to many analysts, one of the most significant changes in Internet markets is a dramatic decrease in consumer search costs (Bakos 1997). On the Internet, it is argued, competing retailers are "just a click away" and customers will benefit from this convenience — at the expense of retailers - by being able to quickly compare prices and product offerings across dozens of retailers to find the best deal.

Shopping robots, or shopbots for short, are thought to be a significant driver of these lower search costs. Internet shopbots are automated tools that allow customers to search for prices and product characteristics from online retailers at a click of a button. Product information is typically queried directly from retailers and presented in formatted price comparison tables, allowing the customer to evaluate the characteristics of available products and click-through directly to their chosen retailer.

Shopbots raise a series of interesting questions for marketing researchers analyzing electronic markets. First, how will consumers respond to the presence of shopbot services and to the information presented by shopbots? A variety of researchers have found that search intensity is surprisingly low in electronic markets (e.g. Johnson et al 2000). Will the presence of shopbots 
significantly alter consumer search behavior? To what extent will price, brand, and other aspects of the product bundle drive the choice of customers who do use shopbots?

Second, how should retailers adjust the elements of their marketing mix in response to shopbots? Will shopbots place significant price pressure on retailers or can retailers effectively differentiate their offers on other dimensions? Can retailers use shopbots to price discriminate across customer groups? Can retailers use low margin items listed at shopbots as an advertising vehicle for other higher margin products sold on their web pages?

Third, how should the shopbots design and price their services to achieve profitability? While shopbots were initially thought to serve the interests of customers alone, their revenue model is typically built on commissions and direct payments from retailers. How should shopbots balance these competing interests?

I analyze these questions by reviewing and synthesizing the relevant academic literature on shopbot services. Early predictions, such as the preceding quote from the Wall Street Journal, argued that shopbots would dramatically increase pricing pressure on retailers, commodify markets, and limit the value of retailer brands. A review of the academic literature suggests that, while shopbots place pressure on retailer margins in some settings, the stark predictions regarding the impact of shopbots ignore three important factors.

First, the spatial and temporal separation between customers, retailers, and product imposed by electronic markets means that service quality is an important product attribute even for otherwise 
homogeneous physical goods (Brynjolfsson and Smith 2000). ${ }^{1}$ Retailer heterogeneity in service levels presents a significant source of asymmetric information for Internet consumers when searching for the "best deal" and appears to drive customer behavior at shopbots.

Second, and similarly, while it is easy for shopbots to communicate some product characteristics, such as price, others, such as service quality and reliability, are more difficult to communicate. In effect, the Internet does not uniformly lower search costs for all aspects of the product bundle. This represents an opportunity both for retailers and shopbots in terms of how to display information to customers.

Third, because of their business models, shopbots have divided loyalties between the interests of customers and retailers. These divided loyalties may explain why recent changes in shopbot interfaces seem to make it more difficult for customers to find the lowest price. For these reasons, in contrast to many early predictions the ultimate impact of shopbots on electronic markets may look more like an "arms race" (Bakos 1998) where both customers and retailers are given more powerful weapons to achieve their respective goals.

The remainder of the paper proceeds as follows. Section 2 discusses the characteristics of shopbot services and reviews their development over time. Section 3 discusses the response of customers to the existence of shopbots and the information they provide. Section 4 discusses the strategic options available to retailers in the presence of shopbots. Section 5 analyzes the incentives of shopbots and their impact on shopbot service. Section 6 concludes and identifies areas for future research.

\footnotetext{
${ }^{1}$ Heterogeneity in service may also explain the high levels of dispersion observed in Internet markets for otherwise homogeneous physical products (e.g., Bailey 1998a, 1998b; Brynjolfsson and Smith (2000a); Clay, Krishnan, and Wolff 2001; Pan, Ratchford, Shankar 2001).
} 


\section{Shopbot Background}

The first Internet shopbot, Bargain Finder, was developed in 1995 by Jeff Leane as an internal project for Andersen Consulting. Commercial shopbots such as Acses.com and MySimon.com appeared shortly thereafter. Most early shopbots gathered prices for books and CDs, low priced homogeneous physical goods with unique tracking numbers. More recent shopbots have expanded into a variety of products and services in $\mathrm{B} 2 \mathrm{C}, \mathrm{B} 2 \mathrm{~B}$, and $\mathrm{C} 2 \mathrm{C}$ markets (Table 1).

Table 1: Products and Representative Shopbots

\begin{tabular}{|c|c|}
\hline Product Category & Representative Shopbots \\
\hline \multicolumn{2}{|c|}{ Business To Consumer Products } \\
\hline Consumer Goods & BizRate, MySimon, Dealtime, PriceScan \\
\hline Computer Components & PriceWatch \\
\hline Automobiles & GM BuyPower \\
\hline New Musical Instruments & GearPrice \\
\hline Pharmaceuticals & DestinationRx, PillBot \\
\hline \multicolumn{2}{|c|}{ Business To Consumer Services } \\
\hline Home Improvement & Improvenet \\
\hline Car Insurance & LowestPremium \\
\hline Moving & MonsterMoving \\
\hline Life Insurance & Discount-life-insurance, BudgetLife \\
\hline Banking and Financial Services & Bankrate \\
\hline \multicolumn{2}{|c|}{ Consumer To Consumer } \\
\hline Auctions & BidXS, AuctionWatch, AuctionBeagle \\
\hline Used Musical Instruments & PrePal \\
\hline \multicolumn{2}{|c|}{ Business To Business } \\
\hline Business Supplies & BuyerZone \\
\hline Hospital Equipment & e-botz \\
\hline
\end{tabular}

It is possible to categorize shopbot design into three generations: stand-alone, contextual, and personalized (Table 2). Stand-alone shopbots only provide comparison information across retailer offerings, as opposed to providing information about the product itself. Thus, customers must come to stand-alone shopbot sites having already determined which product they are interested in purchasing. 
Table 2: Shopbot Taxonomy

\begin{tabular}{|c|c|c|}
\hline Category & Description & Examples \\
\hline Stand-Alone (Unbiased) & $\begin{array}{l}\text { Price comparison separate from } \\
\text { product information, offers } \\
\text { sorted by price }\end{array}$ & PriceScan \\
\hline Stand-Alone (Biased) & $\begin{array}{l}\text { Price comparison separate from } \\
\text { product information, offers } \\
\text { sorted by retailer promotional } \\
\text { spending }\end{array}$ & MySimon, Dealtime, BizRate \\
\hline Contextual & $\begin{array}{l}\text { Associate price comparison } \\
\text { search with product information }\end{array}$ & $\begin{array}{l}\text { CNET Shopper, EdgeGain, } \\
\text { Click-the-Button, Books.com }\end{array}$ \\
\hline Personalized & $\begin{array}{l}\text { Personalize prices, product } \\
\text { search, or display of results. }\end{array}$ & $\begin{array}{l}\text { Frictionless.com Value Shopper, } \\
\text { IBM Information Economies } \\
\text { Project }\end{array}$ \\
\hline
\end{tabular}

Originally stand-alone shopbots offered unbiased listings of products, typically sorted based on price. The revenue model of these shopbots was based on banner advertisements and retailer commissions (typically 3-5\%) for sales generated through the shopbot's site.

However, in late 2000 and early 2001 most shopbots migrated to biased listings where retailers can pay a fee for priority positioning in the shopbot's comparison tables. This changes was in part an acknowledgement of the importance of retailers to the survival of shopbots. Josh Goldman, President and CEO of MySimon, observes: "It's hardly a recipe for success if your bot focuses only on price, and [retailers] have the perception that you're out to destroy their brand."2 This move has also enhanced the revenue options available to shopbots. Currently, fees for placement currently comprise $40 \%$ of a typical shopbot's revenue (Tedeschi 2001). ${ }^{3}$

One disadvantage of stand-alone shopbots is that customers must go to a different site (typically a retailer's site) to learn about the product's characteristics. This gives retailers an extra opportunity to lure customers away from comparing prices. To alleviate this problem, some

\footnotetext{
${ }^{2}$ Quoted in Kirsner, Scott. "Shopping Bots Are Back," May 14, 1999, on CNN.com.

${ }^{3}$ With the remaining $60 \%$ split between banner advertisements $(50 \%)$ and commissions on referred sales (10\%).
} 
second generation shopbots are co-locating product information with their price comparison services. Providing price comparing in the context of product information can come in the form of locating the information on the shopbot site, collocation of the price comparison engine with retailer sites, and retailer-sponsored price comparison.

CNET is a typical example of the first strategy. CNET is a technology product information destination site and in 2000 paid $\$ 700$ million to purchase MySimon. It now uses MySimon’s technology to allow CNET customers to compare prices on the products they are reading about.

EdgeGain, ClicktheButton, and EvenBetter Express, are examples of the second strategy. These services began appearing in 1999 and use browser plug-ins to collocate their price comparison with retailer product information (Figure 1). The plug-in program determines when a customer is searching on a product at popular retailers, such as Amazon.com, and in the background conducts a search for prices and product characteristics at competing retailers. To compare prices the customer must only click a button at the bottom of their browser screen.

Price comparison services initiated by retailers are a third example of contextual shopbots. For example, the now defunct retailer Books.com had a service that allowed customers to compare Books.com's prices to the prices offered by other leading book retailers. Likewise, GM BuyPower allows customers to compare prices and features with other automaker's offerings. Initially, it might seem surprising that retailers would want to sponsor customer search of competitor's products. However, there are two possible reasons for this behavior suggested in the literature. First, Smith, Bailey, and Brynjolfsson (2000) observe that Books.com's behavior is consistent with price discrimination using the consumer's willingness to request and wait for 
price quotes as a signal of high price sensitivity. Second, Urban, Sultan, and Qualls (1999) show that offering unbiased comparisons with competing products may build trust among customers.

Figure 1: Contextual Shopbot Services

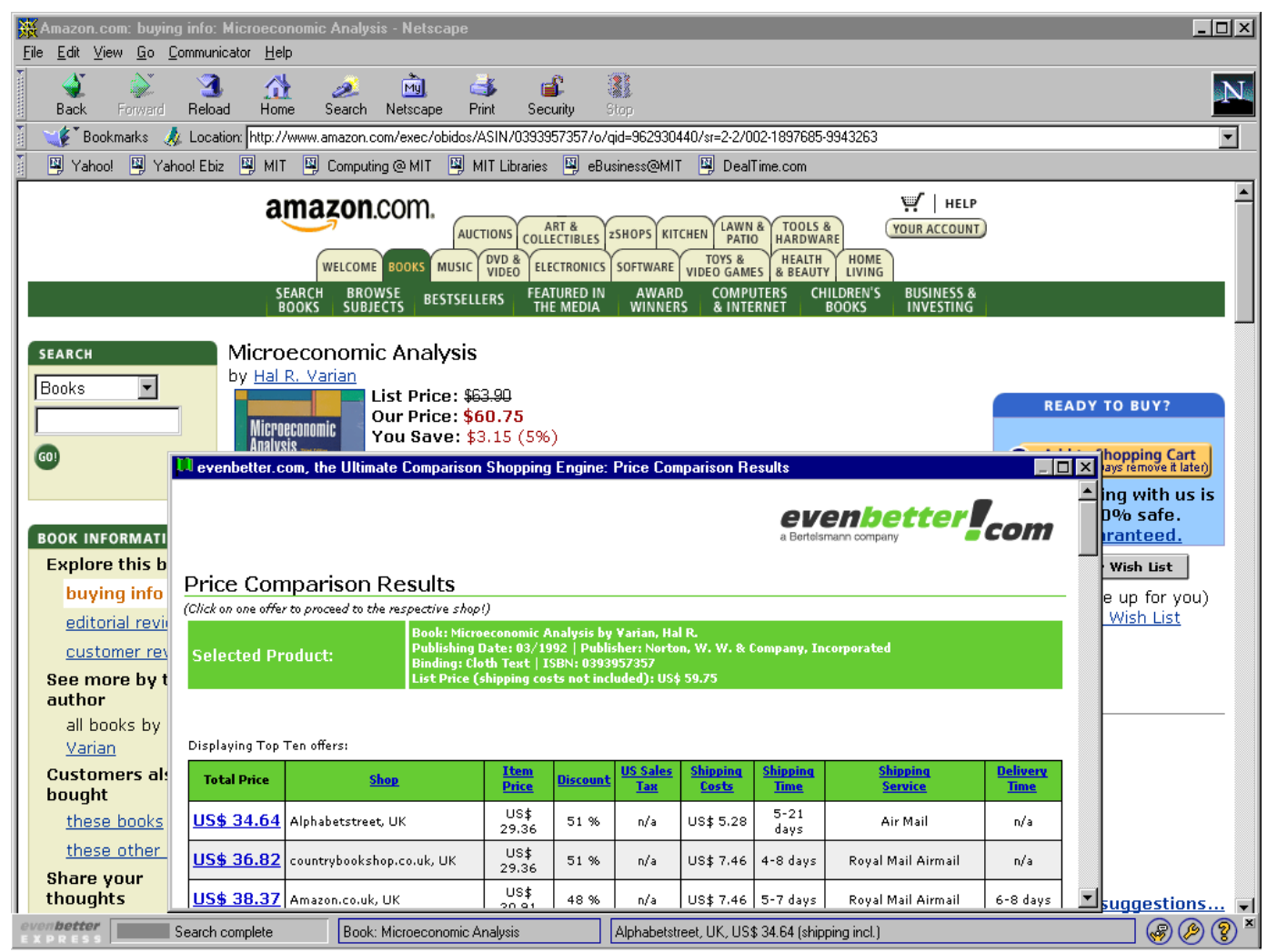

The third generation of shopbot services personalize offers to the preferences of individual consumers. The ValueShopper service offered by Frictionless.com is one example of a personalized shopbot. ValueShopper compared differentiated products on the basis of a value score personalized to the customer's preferences. To use ValueShopper, customers would first answer questions about their preferences for price and features. For example, a digital camera shopper would enter their desired operating system compatibility, display and storage preferences, and target price and price sensitivity levels. The system would then return available products sorted based on a "value score" based on the customer's responses (Figure 2). 


\section{Figure 2: ValueShopper Personalized Shopbot}

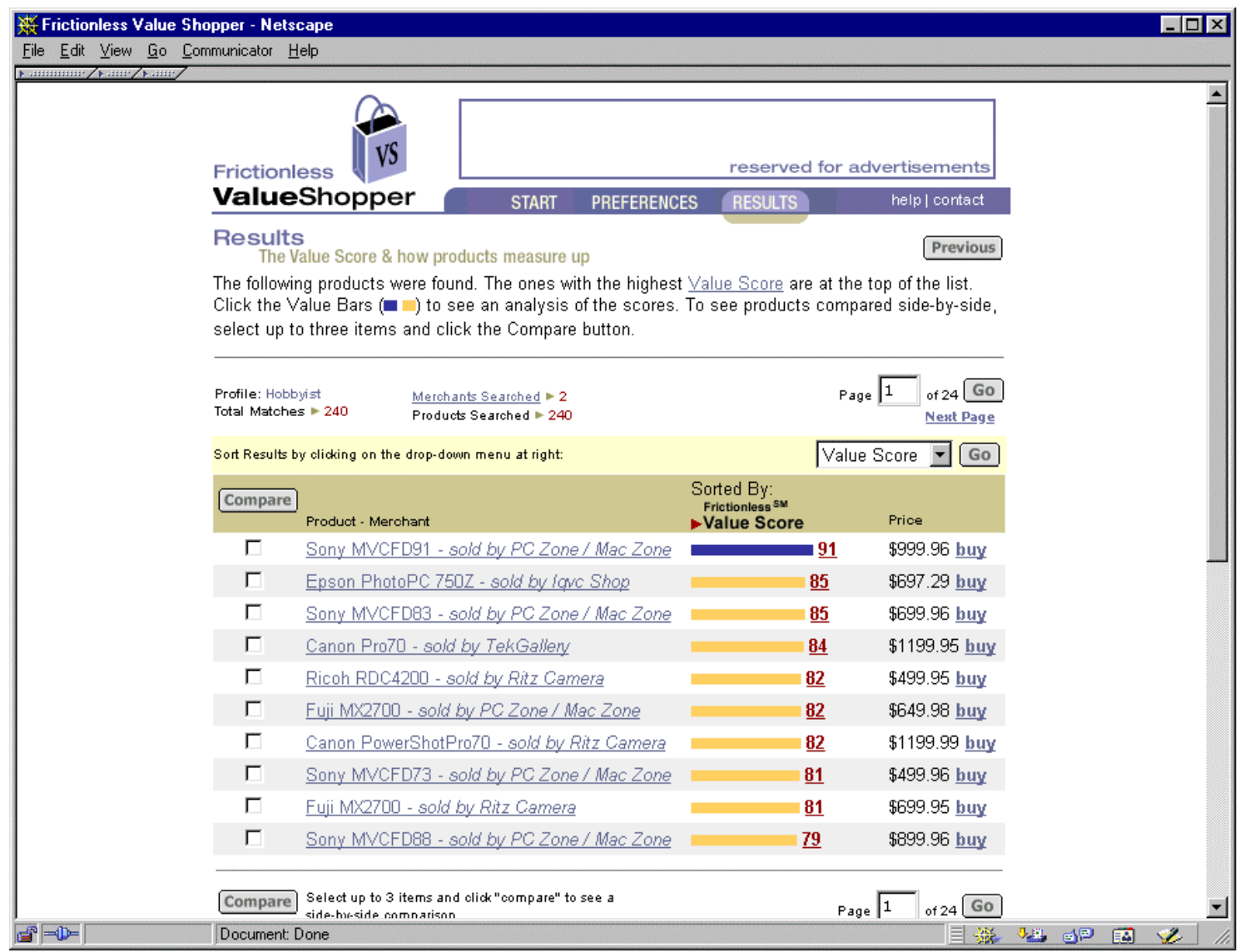

Two academic papers have proposed other bases for personalization. Greenwald and Kephart (1999) argue that pricebots may evolve to complement shopbot services in future Internet markets. Pricebots are retailer and customer initiated tools that negotiate price adjustments based on market conditions and customer characteristics. Montgomery et al (2001) suggest that it may be possible for shopbots to improve their interfaces by learning customer preferences for product characteristics and by personalizing the display and ordering of price comparison tables in response to these characteristics. Such a service would have the potential to both enhance the customer experience and build lock-in for the shopbot's services. 


\section{The Impact of Shopbots on Consumer Behavior}

The early predictions regarding the impact of shopbots have been correct in at least one way: some shopbot customers appear to be very price sensitive. Ellison and Ellison (2001) provide dramatic evidence of this. The authors analyze the behavior of customers at Pricewatch.com, a shopbot for computer components, in late $2000 .^{4}$ Ellison and Ellison track the lowest 12 to 24 prices displayed on Pricewatch for selected low, intermediate, and high quality SDRAM modules, and match prices to sales through a Pricewatch retailer during the same time period.

The authors use these data to investigate demand elasticity using a negative binomial regression of the daily quantity purchased for each product onto the order the offer was displayed in the table, product price, prices of competing modules, and whether the retailer had the lowest price. The authors find own price elasticities of between -6 to -8 for intermediate and high quality memory and -51.8 for low quality memory modules. The authors note that the latter estimate is "the largest demand elasticity we have seen empirically estimated."

These elasticities strongly suggest that shopbot customers at Pricewatch.com are price sensitive and as a result, retailers who list with Pricewatch will only be able to sustain narrow profit margins. For example, assuming a static Nash equilibrium, the Lerner index yields markups of between $12-17 \%$ for the higher quality memory modules and motherboard and $2 \%$ for the low quality memory module.

However, it is also important to note that these results are obtained in a unique environment. Unlike markets for consumer products such as books, music, videos, and home electronics, the

\footnotetext{
${ }^{4}$ Pricewatch differs from a typical shopbot in the sense that retailers upload their product prices to the shopbot as opposed to having the shopbot query prices from the retailers' web pages. However, this distinction does not change the way the prices are displayed to the customers.
} 
market for computer hardware components is unconcentrated and has relatively undifferentiated retailers. Furthermore, shoppers for these products are predominantly computer hobbyists and thus might be more technologically sophisticated than a broader Internet population.

In the online book market, Smith and Brynjolfsson (2001) analyze customer choice data for nearly 40,000 searches for books conducted at Dealtime.com in late 1999. While the authors find that price is the strongest predictor of customer choice behavior and $49 \%$ of customer choose the lowest price, they also find evidence that brand and loyalty are important factors driving customer choice. This is reflected in three ways.

First, modeling customers' latent utility as a function of price, delivery time, and retailer fixedeffects, the authors find strong positive coefficients for the three most heavily advertised retailers: Amazon, Barnesandnoble, and Borders. In dollar terms Amazon holds a $\$ 1.72$ (5\%) price advantage of "generic" retailers and a $\$ 1.30(3 \%)$ price advantage over their two closest rivals, Barnesandnoble and Borders.

Second, the authors find evidence that shopbot customers use brand as a proxy for noncontractible aspects of the product bundle such as shipping reliability. To the extent that customers do not know a priori which retailers have reliable shipping services, standard marketing and economic models suggest that customers will use brand as a proxy for this missing information (e.g., Milgrom and Roberts 1986, Wernerfelt 1988). Consistent with this, after controlling for differences in the quoted delivery times, the authors find that customers who sort on shipping time are four times more sensitive to heavily branded retailers.

Finally, in a separate paper (Brynjolfsson and Smith 2000b) the authors use a cookie numbers to track the loyalty of customers to retailers they had selected on previous visits. They find that 
retailers who were selected on a previous visit by a particular customer hold a $\$ 2.50$ price advantage over other retailers on subsequent visits by that customer.

\section{The Impact of Shopbots on Retailer Behavior}

The most obvious potential impact of shopbots on Internet retailers is to increase pressure on margins. For example, Bakos (1997) uses an analytic model to show that in equilibrium lower search costs lead to lower and less dispersed retailer prices, an effect that is more significant for homogeneous goods. While not a model of shopbot competition specifically, to the extent that shopbots lower customer search costs one might expect to also see lower prices.

Brown and Goolsbee (2000) provide evidence that this may have occurred following the introduction of shopbots for term life insurance policies in 1996. The authors use data on transacted prices for term life insurance matched through demographic characteristics to data on Internet and life insurance comparison site usage for the time period 1992 to 1997. They correlate this data with the development in 1995 of shopbots for life insurance and find that the rise of shopbots reduced term life insurance prices by 8 to 15 percent from 1995 to 1997. Significantly, prices did not decline with increasing Internet use before shopbots were introduced, prices fall faster among demographic groups with high Internet use, and no price decline is observed for whole life insurance policies, which are not tracked by shopbots.

At the same time, Brown and Goolsbee observe that the initial introduction of these shopbot services is associated with an increase in price dispersion. Increased price dispersion as a result of shopbot use is consistent with retailers setting prices in a mixed strategy equilibrium in the presence of informed and uninformed customers. Mixed strategy equilibria of this form are well known in the economics literature (e.g., Salop and Stiglitz (1977), Stahl (1989), and Varian 
(1980)). In these models some consumers are fully informed of all prices and purchase from the lowest priced retailers, while other customers are only informed of one price and can search for additional prices at a cost. In equilibrium, firms respond by drawing prices from a $\mathrm{U}$-shaped distribution. In effect, sometimes retailers charge a high price to maximize revenue from their share of the uninformed customers and sometimes retailers charge a low price to maximize sales from informed customers. Greenwald and Kephart (1999) apply these models to an Internet environment by using simulations to show that in the presence of shopbot and loyal customers retailers optimally set prices in a U-shaped distribution.

Subsequent research extends Greenwald and Kephart's work to analyze other strategic decisions by retailers. Iyer and Pazgal (2001) show that shopbots do not necessarily have to lead to lower prices in Internet markets. The authors model retailers' choices regarding prices and whether to list their prices at a shopbot. In their model, some retailers choose to list their products with shopbots and set prices in a mixed strategy equilibrium. Other retailers choose not to list at shopbots and charge high prices to their loyal customers. An important feature of their model is that average prices increase as the number of retailers who list with the shopbot increase. This is because as competition at the shopbot increases, the probability of gaining sales by charging a low price decreases.

It should be noted that the authors assume that retailers are constrained to charge the same price at shopbots and at their web sites. While this is common among current shopbots, there are no legal or technical reasons why shopbots couldn't price discriminate between shopbot and web site customers. In the context of price discrimination, Chen and Sudhir (2001) use an analytic model where retailers use lack of search through shopbots as a signal of loyalty. In this environment retailers price discriminate between shopbot and non-shopbot customers with 
targeted prices. The authors also show that the presence of shopbots can reduce competition between firms and increase profits because firms are better able to target customers.

Another potential retailer response is to proactively reduce the effectiveness of consumer search through shopbots. Ellison and Ellison (2001) document a variety of obfuscation and bait-andswitch strategies adopted by retailers who list price at Pricewatch.com. The bait in this setting is an inefficiently low quality component with a low price and the retailer's goal is to get customers to switch to a product with a higher margin once they have clicked through to the site. For example, many of the memory modules with low prices on Pricewatch have very high failure rates compared to modules with wholesale prices of a few pennies more. This fact is not apparent to customers looking at the Pricewatch listings but is highlighted on the retailers' sites. In addition, many low priced items are sold in "as is" condition, without standard equipment (e.g. without cooling fans in the case of CPUs), or are sold with high restocking fees, high shipping costs, or long delivery times. Most importantly, the retailers sell higher priced products without these restrictions. Ellison and Ellison find evidence that these bait-and-switch strategies are effective. Cross-price elasticity between low quality and intermediate quality memory modules is large and negative in contrast to what would be expected for economic substitutes.

There are a variety of other ways retailers could reduce the effectiveness of search at shopbots. One simple example is by encouraging shopbots to sort tables based on retailer advertising rather than price, as is common in most current shopbots. Another possibility is to encourage manufacturers to increase their use of branded variants (Bergan, Dutta, Shugan 1996) to make direct comparison of products more difficult. 


\section{The Strategic Position of Shopbots in Internet Markets}

As noted above, in their revenue models shopbots are beholden to the interests of both customers and retailers. Retailers provide product listings and increasingly provide payments for priority positions in price comparison tables. Customers provide eyeballs to view banner advertisements and commissions through purchases made at retailer sites. In this environment, shopbots are faced with difficult decisions about how to set prices and design their shopping interfaces.

Baye and Morgan (2001) use an analytic model to examine the incentives of shopbots in this context. In their model retailer offerings are entirely homogeneous and shopbots can choose the fees they will charge both retailers and customers to use their services. The authors find that shopbot profits are maximized in the presence of price dispersion and when prices are set such that all customers use the shopbot. The intuition for this finding is that, more consumers lead to higher profits and, in the absence of price dispersion, consumers would have no reason to search for lower prices. The authors also show that profits are maximized when prices are set such that not all retailers use the shopbot. The intuition for this finding is that if all retailers used the shopbot, competition would drive prices to zero and would eliminate shopbot profits. ${ }^{5}$

Another interesting question shopbots face is how to present product information to customers. To this end, Montgomery et al (2001) use choice models and empirical data from Dealtime.com to show that shopbots can significantly improve consumer utility by intelligently querying and displaying retailer offers. The authors find that the modal wait time from search to the display of prices at a shopbot is 45 seconds and that $10 \%$ of queries timeout at 3 minutes. Furthermore, retailers can estimate likely prices since most retailers follow predictable pricing patterns and rarely change prices. In this setting, the authors recommend that shopbots shorten customer wait

\footnotetext{
${ }^{5}$ Ellison and Ellison (2001) and Iyer and Pazgal (2001) have similar findings.
} 
times by evaluating which retailers are likely to return the best deals and using this information to selectively query retailers and proactively terminate query threads for retailers who are slow to respond. Further, because of the high cognitive costs associated with processing additional offers and additional attributes, retailers should be selective about the number of offers and product attributes they display.

\section{Conclusions and Areas for Future Research}

Many analysts initially projected that shopbots would shift the balance of power in online markets toward consumers. However, the academic research is far from unanimous on this point.

With regard to customer behavior at Internet shopbots, recent research has shown that while some shopbot consumers are highly price sensitive, shopbot consumers also tend to prefer heavily branded retailers and retailers they have dealt with on previous visits. This could be evidence that, in spite of the wealth of information provided by shopbots, shopbot customers remain asymmetrically informed about critical product attributes such as service quality and are using brand and prior positive experience as proxies for this missing information.

In terms of retailer behavior in the presence of shopbots, recent studies have found that shopbots place significant pressure on retailer margins in some settings. However, research has also shown that retailers retain a variety of strategic options to mitigate this pressure including strategic pricing, price discrimination, bait-and-switch, and search obfuscation.

Finally, shopbots themselves are in an awkward strategic situation. On one hand they must make search easy to encourage consumers to use their services; on the other hand, they damage their business model if they drive all consumers to the lowest priced retailer or drive price dispersion to zero. In this context, shopbots may be able to maximize their revenue by intelligently 
designing their interfaces to improve consumer search without eliminating retailer differentiation.

There are a variety of ways to extend the academic understanding of the role of shopbots in electronic markets. With regard to consumer behavior, it would be interesting to analyze how shopbot users differ from other Internet customers as a way to evaluate the price sensitivity results obtained in the current literature. Similarly, one could analyze how the presentation of information at shopbots influences customer price sensitivity. Lynch and Ariely (2000) find that interfaces that lower search costs for price information cause customers to be more sensitive to price versus interfaces that focus more on quality information. In this context it would be interesting to analyze whether customer price sensitivity declined after retailer logos and retailer ratings were added to shopbot comparison tables.

It would also be interesting for future research to analyze how the presentation of partitioned prices impact customer choices. Smith and Brynjolfsson's (2001) results suggest that customers are more sensitive to shipping price and sales taxes than they are to the price of the item. Morwitz, Greenleaf, and Johnson (1998) find that the reverse is true when it is cognitively difficult for customers to associate the base price (e.g., item price) with the surcharge (e.g., shipping price and taxes). Thus, eliminating the cognitive costs from associating base prices and surcharges may reverse customer sensitivity in some circumstances. More work in this area would be useful in light of recent well-publicized efforts by retailers such as Amazon.com to highlight their free-shipping policies to certain orders.

Lastly, it would be interesting to analyze in more detail what factors limit customer adoption of shopbots. Montgomery el at (2001) show that one factor limiting customer adoption may be the 
cognitive costs associated with evaluating numerous offers and alternatives (Shugan 1980) and the extra time necessary to use shopbots (Delleart and Kahn 1999, Johnson et al 2000, and Konana et al 2000). Under a reasonable set of assumptions regarding customer disutility associated with delay and cognitive costs, Montgomery et al (2001) find that if customers are presented with offers from 28 different stores, a typical number for current shopbots, $90 \%$ of customers would generate a higher utility from shopping at their favorite store versus using a shopbot. Future empirical or experimental work could analyze the effect of shopbot interface design, particularly delay and cognitive costs, on customer adoption.

With regard to retailer behavior, it would be useful for future work to analyze when it is optimal for retailers to block shopbot services. It is notable that most retailers tracked by BargainFinder in 1995 quickly blocked the service and more recently eBay engaged in a much-publicized lawsuit to block queries from the auction shopbot BiddersEdge. Also, as noted above, retailers may benefit by sponsoring price comparison tools either to target price sensitive customers or to build trust. It would be useful to analyze when and where these strategies are most effective.

With regard to shopbot strategies, it is important to note that most analytic findings regarding shopbots have assumed perfectly homogeneous products. Given that empirical research suggests that even otherwise homogeneous physical products can be differentiated through service quality, it would be interesting for future models to expand their analysis to include differentiated products. It would also be interesting for future research to analyze how shopbots can use the information they are able to gather from customers either by personalizing the display of information to customers based on their preferences or by partnering with retailers to personalize prices based on customers revealed price sensitivity. 
At a macro level, one wonders whether shopbots increase in the information available to consumers in physical markets and how this influences prices in both markets? It would also be useful to understand how the impact of shopbots on B2B markets might differ from B2C markets with regard to buyer behavior, seller response, and shopbot strategies?

Finally, it is important to note that shopbots are at an early stage of development and their impact may change over time with increasing consumer penetration, changes in the concentration of Internet markets, and advances in shopbot design. It will be important for future research to track these changes over time.

In sum, while many questions remain about the influence of shopbots on electronic markets, it is relatively clear that shopbots will remain an important driver of Internet market development and will be an important factor to watch for customers, retailers, and academic researchers. 


\section{References}

Bailey, Joseph P. 1998a. Intermediation and Electronic Markets: Aggregation and Pricing in Internet Commerce. Ph.D. Dissertation, Technology, Management and Policy, Massachusetts Institute of Technology, Cambridge, MA.

Bailey, Joseph P. 1998b. "Electronic Commerce: Prices and Consumer Issues for Three Products: Books, Compact Discs, and Software." Organisation for Economic Co-Operation and Development, OCDE/GD 98(4).

Bakos, J. Yannis. 1997. "Reducing Buyer Search Costs: Implications for Electronic Marketplaces.” Management Science 43(12):1613-1630.

Bakos, J. Yannis. 1998. "The Emerging Role of Electronic Marketplaces on the Internet." Communications of the ACM 41(8):35-42.

Baye, Michael, John Morgan. 2001. "Information Gatekeepers on the Internet and the Competitiveness of Homogeneous Product Markets." American Economic Review 91(3):454474.

Bergan, Mark, Shantanu Dutta, and Steven Mark Shugan. 1996. "Branded Variants: A Retail Perspective." Journal of Marketing Research 33(1):9-19.

Borzo, Jeanette. 2001. Searching: Out Of Order? Wall Street Journal, September 24, Page R13.

Brown, Jeffrey R., Austan Goolsbee. 2000. "Does the Internet Make Markets More Competitive? Evidence From the Life Insurance Industry." National Bureau of Economic Research Working Paper \#7996, October.

Brynjolfsson, Erik, Michael Smith. 2000a. "Frictionless Commerce? A Comparison of Internet and Conventional Retailers.” Management Science 46(4) 563-585.

Brynjolfsson, Erik, Michael Smith. 2000b. "The Great Equalizer? Customer Choice Behavior at Internet Shopbots.” Working Paper, MIT Sloan School of Management, Cambridge, MA.

Chen, Yuxin, K. Sudhir. 2001. "When Shopbots Meet Emails: Implications for Price Competition on the Internet." Working Paper, New York University, New York, NY.

Clay, Karen, Ramayya Krishnan, Eric Wolff. 2001. "Price Strategies on the Web: Evidence From the Online Book Industry." Journal of Industrial Economics 49(4):521-540.

Dellaert, Benedict G. C.; Kahn, Barbara E. 1999. "How Tolerable is Delay? Consumers' Evaluations of Internet Web Sites after Waiting." Journal of Interactive Marketing 13(1):41-54.

Ellison, Glen; Sara Fisher Ellison. 2001. "Search, Obfuscation, and Price Elasticities on the Internet.” Working Paper, MIT, Cambridge, MA, January. 
Greenwald, Amy R., Jeffrey O. Kephart. 1999. "Shopbots and Pricebots." The Proceedings of International Joint Conference on Artificial Intelligence.

Iyer, Ganesh, Amit Pazgal. 2001. "Internet Shopping Agents: Virtual Co-Location and Competition." Working Paper, University of California at Berkeley, Berkeley, CA.

Johnson, Eric J., Wendy Moe, Peter Fader, Steven Bellman, Jerry Lohse. 2000. “On the Depth and Dynamics of Online Search Behavior." Wharton Marketing Department Working Paper \#00019, Philadelphia, PA.

Kollock, Peter. 1999. "The Production of Trust in Online Markets." In Advances in Group Processes (Vol. 16). Eds. Lawler, Macy, Thyne, Walker. Greenwich CT: JAI Press.

Konana, Prebhudev, Alok Gupta, Andrew B. Whinston. 2000. "Integrating User Preferences and Real-Time Workload in Information Services. Information Systems Research 11(2):177-196.

Kuttner, Robert. 1998. “The Net: A Market Too Perfect for Profits?” Business Week, May 11, p. 20.

Lynch, John G., Dan Ariely. 2000. "Wine Online: Search Cost Affect Competition on Price, Quality, and Distribution." Marketing Science 19(1):83-103.

Milgrom, Paul; John Roberts. 1986. "Price and Advertising Signals of Product Quality." Journal of Political Economy 94(4):796-821.

Montgomery, Alan L., Kartik Hosanagar, Ramayya Krishnan, Karen Clay. 2001. "Designing a Better Shopbot." Working Paper, Carnegie Mellon University, Pittsburgh, PA.

Morwitz, Vicki, Eric A. Greenleaf, Eric J. Johnson. 1998. "Divide and Prosper: Consumers' Reactions to Partitioned Prices." Journal of Marketing Research 35(November):453-463.

Pan, Xing, Brian T. Ratchford, Venkatesh Shankar. 2001. "Why Aren't the Prices of the Same Item the Same at Me.com and You.com? Drivers of Price Dispersion Among E-Tailers." Working Paper, University of Maryland, College Park, MD, November.

Salop, S., J. E. Stiglitz. 1982. "The Theory of Sales: A Simple Model of Equilibrium Price Dispersion with Identical Agents." The American Economic Review 72(5):1121-1130.

Smith, Michael, Joseph Bailey, Erik Brynjolfsson. 2000. “Understanding Digital Markets.” In Understanding the Digital Economy. Eds. Erik Brynjolfsson and Brian Kahin. Cambridge, MA: MIT Press, 99-136.

Smith, Michael, Erik Brynjolfsson. 2001. "Customer Decision-Making at an Internet Shopbot: Brand Matters." Journal of Industrial Economics 49(4):541-558.

Shugan, Steven M. 1980. "The Cost of Thinking." Journal of Consumer Research 7(September):99-111. 
Stahl, Dale O. 1989. "Oligopolistic Pricing with Sequential Consumer Search.” The American Economic Review 79(4):700-712.

Tedeschi, Bob. 2001. "E-Commerce Report: Comparison Sites Struggling as Well.” New York Times, February 5.

Urban, Glen L., Fareena Sultan, William Qualls. 1999. "Design and Evaluation of a Trust Based Advisor on the Internet." Working Paper, MIT Sloan School of Management, Cambridge, MA.

Varian, Hal R. 1980. “A Model of Sales.” The American Economic Review 70(4):651-659.

Wernerfelt, Birger. 1988. "Umbrella Branding as a Signal of New Product Quality: An Example of Signaling by Posting a Bond." RAND Journal of Economics 19(3):458-466. 